\title{
Using scaffold innovation-thinking frameworks to integrate food science and technology into the transdisciplinary engineering design classroom
}

\author{
Lisa Bosman ${ }^{*}$ and Sangjun Eom
}

\author{
*Correspondence: Ibosman@ \\ purdue.edu \\ Purdue Polytechnic Institute, Purdue \\ University, 155 Grant Street, West \\ Lafayette, IN 47907, USA
}

\begin{abstract}
Technology and innovation are essential for students to not only learn and understand the technical skills, but also identify a problem, discover a solution, and communicate the value proposition. In this study, innovation-thinking frameworks were integrated into undergraduate transdisciplinary engineering and technology classrooms with a topic of food science and technology, exploring design within the area of new product development. The qualitative analysis, conducted using NVivo, indicated that the food science and technology focused educational experiences had the potential of transforming student self-reported perspectives related to metacognitive reflection, connecting the topics to the real-world and communicating. The findings offer exciting insights into the benefit of integrating self-regulated learning, visualization, and communication technology into future food-related education programs.
\end{abstract}

Keywords: Innovation-thinking frameworks, Writing across the curriculum, Transdisciplinary, NVivo qualitative analysis software, Human-centered design

\section{Introduction}

Engineers and technologists play a critical role in the economy by addressing pressing problems and creating solutions that are new and innovative, and requires collaboration and communication. It is a role that involves technical skills but also requires curiosity, an ability to connect pieces of knowledge to discover solutions, and communicate a focus on value creation-which are all characteristic of innovation-thinking frameworks such as entrepreneurial-minded learning (Bosman \& Fernhaber, 2018), systems thinking (Seddon \& Caulkin, 2007), design thinking (Brown, 2009), value proposition canvas (Osterwalder, Pigneur, Bernarda, \& Smith, 2014), and business model canvas (Osterwalder \& Pigneur, 2010). These innovation-thinking frameworks are applicable for both start-ups and employees working within an organization (Wheadon \& Duval-Couetil, 2016), as they emphasize the development of innovation-thinking among the workforce which allows people to identify and solve problems. Because innovation-thinking develops over time and requires practice, the role of educators is

(c) The Author(s). 2019 Open Access This article is distributed under the terms of the Creative Commons Attribution 4.0 International License (http://creativecommons.org/licenses/by/4.0/), which permits unrestricted use, distribution, and reproduction in any medium, provided you give appropriate credit to the original author(s) and the source, provide a link to the Creative Commons license, and indicate if changes were made. 
to discover opportunities throughout a student's coursework to infuse this approach into learning (Beiler, 2015).

One approach to innovation-thinking is through the easily relatable topic of food science and technology. "Food science and technology is the understanding and application of science to satisfy the needs of society for sustainable food quality, safety and security (Campbell-Platt, 2017)." The benefit of exploring and designing around the theme of food science and technology exists in the transdisciplinary nature of food which covers the gamut of business viability and economic analysis, customer desirability and consumer behaviors, and technical feasibility and prototyping. Furthermore, the visual aspect of innovation-thinking frameworks encourages an increased application of information and communications technology to convey the proposed value proposition clearly. Together, innovation, food, and communication technology are complementary attributes to improve inclusion and equity quotas in the engineering and technology classroom.

This paper will explain our unique, yet complementary, dual-course approach to incorporate food science and technology into non-food focused courses, such as the transdisciplinary engineering and technology classroom. The guiding research questions are as follows:

- How can innovative teaching methodologies be applied to food science and technology focused learning experiences to improve student learning outcomes?

- How can food science and technology focused learning experiences encourage students to connect and extend innovation and design frameworks to real-world settings?

- How can the integration of a communication requirement into food science and focused learning experiences develop skills related to oral, written and visual communication?

\section{Literature review}

\section{Benefits associated with food-related education programs}

The quantity of food-related education programs has been on the rise due to numerous benefits include the interdisciplinary ability to bring together topics including business, technology, and consumer sciences, to name a few. Cohen (2010) evaluated a cross-disciplinary undergraduate course that integrates design and liberal arts intending to improve the sustainability of the school's food system. The student and faculty evaluations show that the course was effective and helpful in learning about sustainability and urban systems through research, problem-solving, and communication. In addition, ideas and designs developed as part of the course have resulted in real changes made to the university including the campus installation of several water refill stations and campus cafeteria integration of organic and locally sourced food products. Barlett et al. (2008) conducted research on the Piedmont Project, a multidisciplinary faculty professional development program aimed to integrate sustainability and environmental issues (including food science and technology) into the higher education curriculum. Data collected from ninety faculty participants showed an increased awareness of systems thinking, desire to 
change daily habits, motivation to get more involved in political action, and a value proposition for teaching living systems from a more holistic approach including the natural sciences, social sciences, and humanities. Parr and Trexler (2011) investigated student perceptions related to sustainable agriculture and food sysems (SAFS) education, approaches for integrating student farms into education objectives, and motivation for engaging with student farms. Findings suggest a strong connection to experiential learning theory in that learning was enhanced when the knowledge was co-constructed by learning through both classroom theory and applied fieldwork. As a result of the study, an SAFS faculty, staff, and student community of practice was formed to increase co-construction of knowledge at the farms and throughout campus. Galt, Clark, and Parr (2016) investigated a valuesbased pedagogical approach in the context of sustainable agriculture and food systems (SAFS) for its curriculum design and teaching. The authors suggest three key areas drive value creation including views on SAFS governance, the ability to form learning opportunities, and the role an individual plays within the learning environment. Findings suggest that values can be used as a guiding learning element to promote participatory dialogue, increase awareness around personal thought and use of language, and facilitate agency and empowerment towards civic action. Clark and Button (2011) explored a transdisciplinary methodology of integrating science, arts and aesthetics into sustainability education through university student engagement with the local community. The findings show that the project left participants with a newfound desire for eco-justice, developing sustainable societies, and taking action. Galt et al. (2013) developed and evaluate a new course as part of the SAFS major at University of California Davis. The authors provided an overview of the curriculum (e.g., lectures, assignments, labs, exams, etc...), showing how it relates to student-centered inquiry and social constructivist learning theory. The results demonstrate that the students increased their learning through the inquiry process, and the reflective essays played an important role in reinforcing learning and allowing for instructors to understand the students' perceived learning.

\section{Challenges associated with food-related education programs}

Providing food-related education programs does not come without challenges. Valley, Wittman, Jordan, Ahmed, and Galt (2018) conducted research categorizing pedagogical approaches to sustainable food system education programs. Findings indicate there are limited best practices and critical analysis related to curriculum design and teaching within these types of programs. Berger, Scott, Axe, and Hawkins (2013) assessed the learning outcomes associated with global challenges related to health, hunger, and humanity. The authors uncovered that additional administrative support is required to effectively design and implement courses that would involve more faculty and advance the college's mission. Barlett (2011) evaluated the campus sustainable food projects according to four key factors: purchasing goals, academic programs, direct marketing, and experiential learning. The evaluation shows that the project requires increased long-term and institutional commitment, where efforts are provided beyond the classroom. Burley et al. (2016) conducted a project through a graduate seminar in sociology to help the undergraduate student organization change the university cafeteria by 
providing local and sustainably produced food. The authors faced challenges with resistance from the university's corporate food vendor. Grossman et al. (2012) analyzed the student response from pre- and post-service and their interactions with the diverse and economically disadvantaged populations from a pilot program, the Community Food Security Scholars. The results showed that when a service-learning program was implemented, the students face the challenges of responsibility and support, and often ended up with community-blaming tendencies. Brundiers, Wiek, and Redman (2010) investigated the development and deployment of competency-based education in academic sustainability programs. The authors found that the students faced difficulties of connecting competencies to the real-world learning opportunities.

\section{Recommendations for developing food-related education programs}

Due to the many benefits associated with food-related education programs, researchers have offered many recommendations to overcome the associated challenges and barriers. Brekken, Peterson, King, and Conner (2018) proposed a new framework for a food system course that focuses on five different learning activities, each of which are animated with the examples. The authors found that by practicing the change of cultural and institutional norms from the collaboration of multiple universities, students' expectations on the education and their roles in entering the world problems in the food system increase. Sibbel (2009) conducted a study aimed to overcome the challenges of aligning higher education with sustainability. The findings demonstrate that a minimum level of institutional support is required to achieve sustainability at higher education. Burns (2011) proposed a model of sustainability pedagogy in the context of five key perspectives including content, perspective, process, context, and design. The model shows that its pedagogy can bring a change in the system of sustainability program by producing transformative learning experiences. Jacobsen et al. (2012) assessed the development of a new sustainable agriculture undergraduate major and minor degrees at the land-grant universities. From the results, the authors suggested that faculty, staff, and students needed to be key players in this program development in order to meet the changes in agricultural paradigm. Clark, Byker, Niewolny, and Helms (2013) investigated the development of the interdisciplinary minor in Civic Agriculture and Food Systems at Virginia Tech, which aimed to respond to student interest in sustainable agriculture education. The results show that the program needed to be interdisciplinary, values-based, and experiential in order to advance at the higher education level. Kolodinsky, Fukagawa, Roche, Belliveau, and Johnson (2016) evaluated a transdisciplinary food systems initiative and found a more holistic level of academic support was required to make the project a success. LaCharite (2016) explored different campus agriculture projects in the U.S. in terms of diversity in their characteristics and objectives. The author found that more research on understanding the curricular learning objectives and outcomes was needed to expand agriculture-based education beyond its traditional degrees at the universities.

\section{Summary}

In summary, food-related education programs are on the rise, in addition to research evaluating the associated benefits and challenges. The purpose of this paper is to add to the body of knowledge, highlighting the integrating of innovating-thinking frameworks as a means to apply a greater focus on information and communications technology 
into the engineering and technology classroom. This is an area that has yet to be research. Together, research on innovation, food, and communication technology are complementary attributes to improve inclusion and equity quotas in the engineering and technology classroom.

\section{Methods}

Introduction

In 2016, a research-intensive university located in the Midwest, U.S.A. received official approval to offer a new undergraduate program with a focus on transdisciplinary education provided through two different bachelor degrees: B.S. in Transdisciplinary Studies in Technology (BS-TST) and B.S. in Transdisciplinary Studies in Engineering Technology (BS-TSET). Consistent with other programs offered through the university, each degree requires students to complete a total of 120 credits of which about one-third are general education credits. The remaining two-thirds are split between core credits and free credits. For the core credits, students are required to complete a Design-Studio course and ePortfolio course each semester. For the free credits, students enrolled in the BS-TST major can select any courses from across the university, while the students enrolled in the BS-TSET major are limited to courses offered through the School of Engineering Technology. This approach to education allows students to integrate a variety of disciplines from humanities to technology and approach problem-solving from a more holistic and human-centered perspective. Each semester, the students get to experience learning from a variety of themes including Play, Transportation, Renewable Energy, to name a few. In Fall 2018, the theme was Food.

\section{Study design}

The Fall 2018 Design-Studio course explored food science and technology through three different topic areas including food evolution, the food supply chain, and food waste. The course was project-based, and each topic resulted in the creation of a technology-integrated artifact. The learning approach included guest lectures from other departments, field trips, and discussions of assigned readings.

For the first topic students were introduced to an evolution of food science and technology. Content included the science behind cooking, genetically modified organisms (GMOs) and innovations in kitchen equipment. Students read Taste by Barb Stucky and 101 Things I learned in Culinary School by Louis Eguaras. In this first topic, a faculty member from the School of Engineering Technology provided several guest lectures on milling and molding. In addition, students had the opportunity to participate in sensory tests and cooking experiments through a field trip to the campus Department of Food Science labs. At the end of the topic, students were required to design and prototype a piece of cooking equipment by using computer-aided design (CAD).

The second topic focused on how the supply chain of food industry worked on the distribution of products. Faculty members from the Department of Technology Leadership and Innovation, and the Department of Entomology joined the classroom as guest lecturers. In addition, students participated in field trips to a local farm and campus Department of Entomology labs. Students actively engaged in the "Water Game" by 
using SAP software. During this simulation, student teams finalized and revised the price and stock of the water bottles for sale in an attempt to maximize profit.

The third topic was focused on food insecurity in the context of consumption and waste. Students discussed case studies during a guest lecturer from the campus research park. Also, students engaged in multiple reading discussions based on the books including American Wasteland by Jonathan Bloom and Word of Mouth by Andy Sernovitz. As a final project, students were grouped up to create an "Assistive Planter," a small-scale technology-integrated ecosystem that utilized the efficiency of the plant growth and conservation.

The Fall 2018 ePortfolio course had two main components. One component was a learning experience aimed to assist students with developing an elevator pitch, highlighting students' individualized value they have to offer employers and techniques for delivering this well-known approach to quickly communicating with potential future employers. The other component guided students through the self-regulated learning process using the context of food science and technology. At the beginning of the semester, students were given a design challenge: "How might University students, faculty, staff, and visitors better access healthy and affordable food?". The students participated in a series of four scaffold modules (visually shown in Fig. 1 to enunciate the "scaffold" nature of the project where each framework builds on the next): (1) Systems

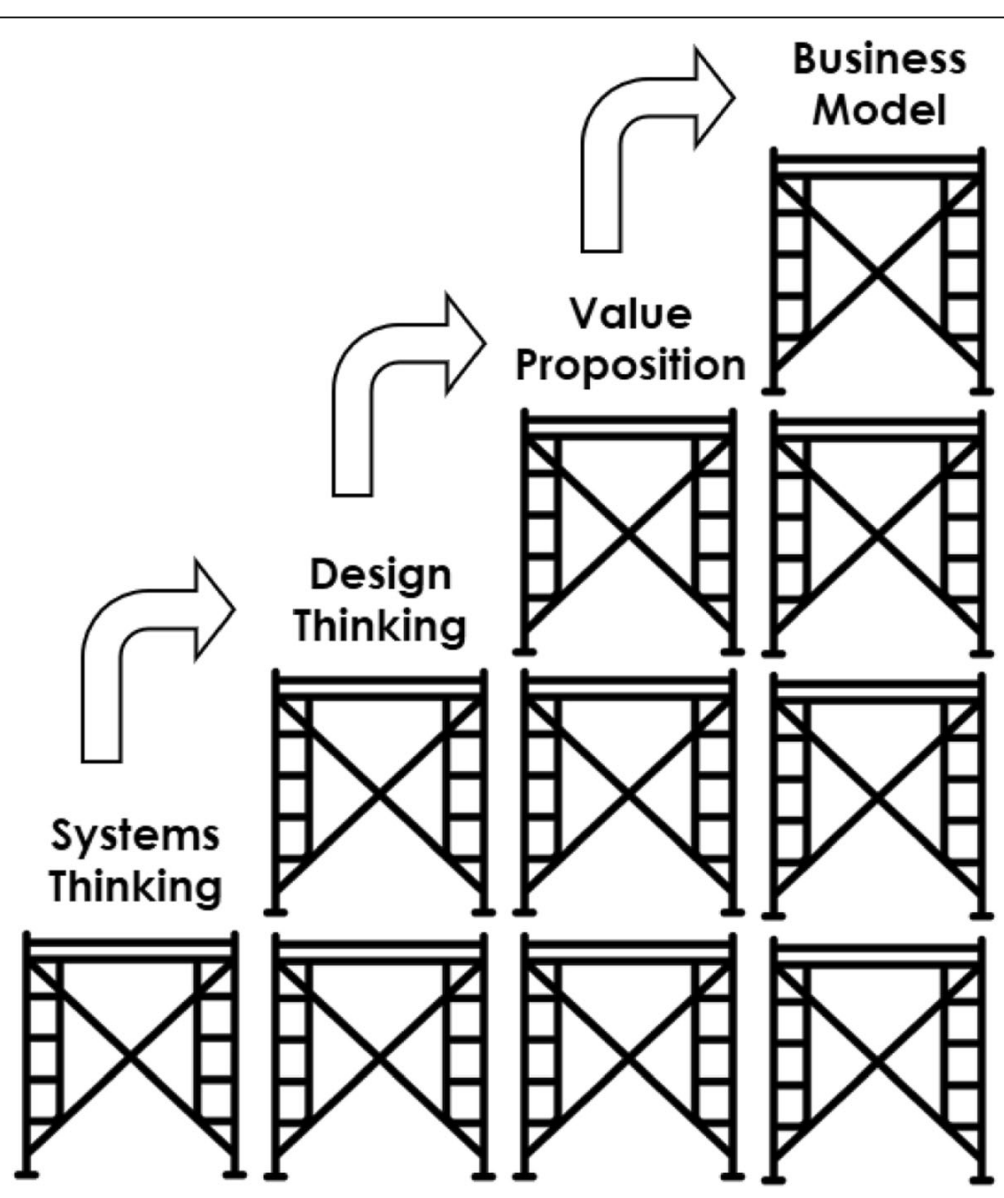

Fig. 1 Scaffold Modules 
Thinking, (2) Design Thinking, (3) Problem solving, and (4) Entrepreneurial Thinking. This scaffold and funnel approach to design and innovation was intentionally applied to guide students from a (a) big picture, endless problems, system's level perspective to (b) problem-solution fit exploration to (c) problem-solution fit identification to (d) commercializing a solution. Each module included a human-based design activity incorporating a new framework (visually shown in Fig. 2 to reference the specific framework used) and information obtained from interviewing other potential customers. Also, each module required students to submit a five-page reflection responding to a set of self-regulated learning reflection prompts.

\section{Participants}

All participants were enrolled full-time at a research-intensive university located in the Midwest, U.S.A. Students enrolled in the Design-Studio and ePortfolio courses were required to participate in the research as part of their assignment. Ten students participated in the study, including five females and five males. Both courses were vertically integrated, where students across all grade levels enroll in the class. Three of the participants were freshmen and new to the university, three were sophomore level students, three were junior level students and one was a senior level student. The study design was approved by the university Institutional Review Board (IRB) \#1808020877 as

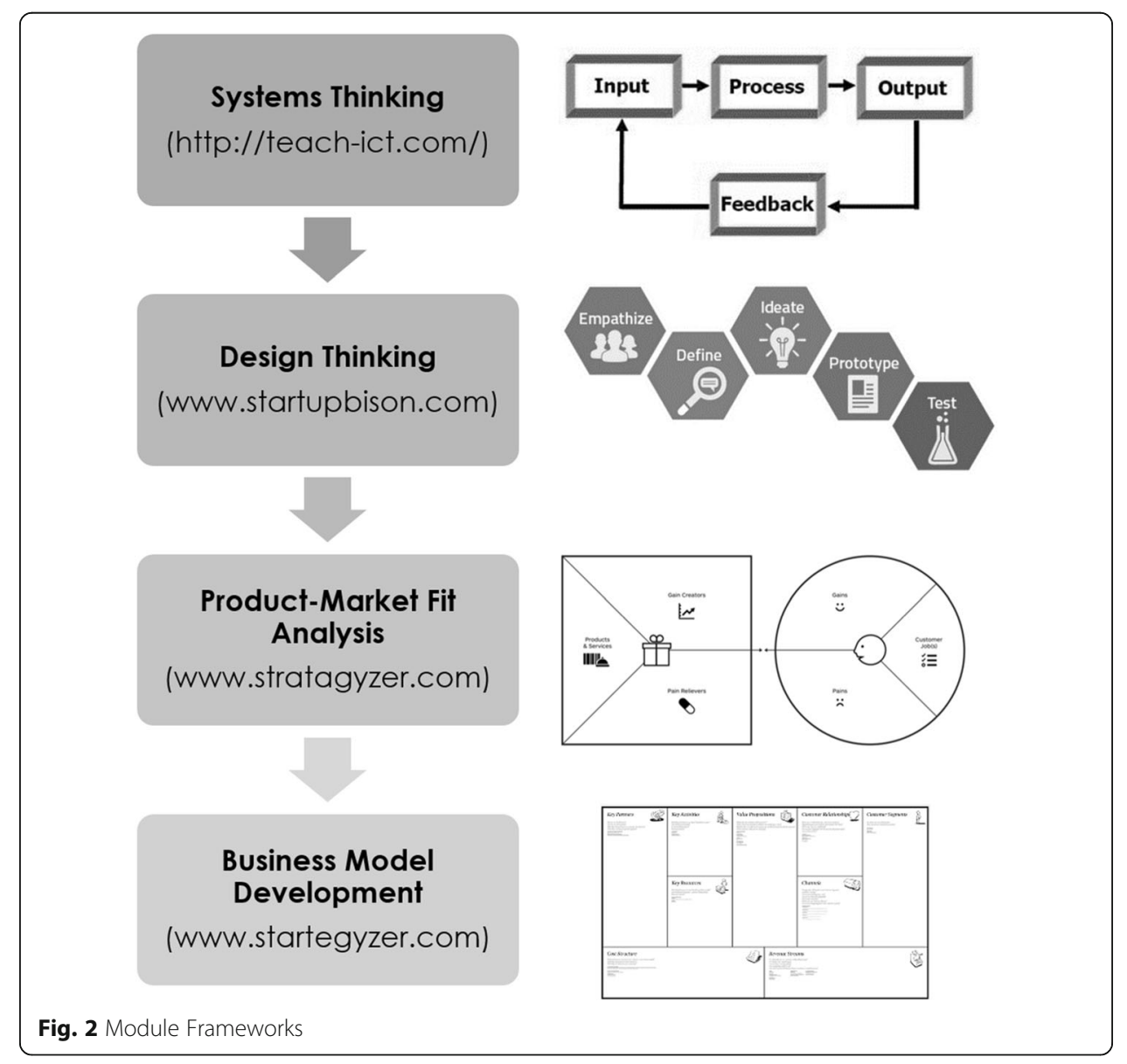


Exempt Category (1). As a result, students were notified that the class assignment would be used for research purposes.

\section{Data collection}

Two different research instruments were used including (1) pre- and post-philosophy of learning statements and (2) reflection prompts.

\section{Pre- and post-philosophy of learning statements}

This instrument collected data responding to the research question: How can innovative teaching methodologies be applied to food science and technology focused learning experiences to improve student learning outcomes? Before starting coursework (for both the Design-Studio and ePortfolio courses) and at the end of the semester, students completed a pre- and post-philosophy of learning statement. The open-ended survey questions are provided here.

1. When faced with a learning opportunity, how do you assess barriers and motivators, and overall ability to complete the task within a timely manner? [2-3 sentences]

2. How do you decide what you need to learn and the overall approach to learning? [2-3 sentences]

3. Upon completing a learning experience, how do you know if it was worth learning? [2-3 sentences]

4. If you were to participate in a similar learning experience again, would you approach learning it in a different way? Explain. [2-3 sentences]

\section{Reflection prompts}

This instrument collected data responding to the research questions: How can food science and technology focused learning experiences encourage students to connect and extend innovation and design frameworks to real-world settings? How can the integration of a communication requirement into food science and focused learning experiences develop skills related to oral, written and visual communication? Throughout the semester, students were required to submit four essays (minimum of 5 pages in length, double spaced, Times Roman Numeral 12 pt. font) responding to reflection prompts linked to innovation and technology frameworks including systems thinking, design thinking, value proposition canvas, and business model canvas. Example reflection prompts are provided here:

1. Prior to starting the assignment, identify your strengths and weaknesses with respect to assessing the task (your ability to complete the three steps within a timely manner). Provide evidence and justification to support the identified strengths and weaknesses.

2. What did you learn about your ability to self-assess? What did you learn about the assignment topic? What did you learn about yourself in comparison to your peers? Did you increase a level of competence for a concept or skill?

3. Assume you are given a similar assignment again in the future [by your employer], describe how you might approach the task differently to improve upon your learning 
experience [and convince your employer of the value you might offer]. How might the concept or skills required for this assignment be applied in a real-world setting?

4. What will you do as a result of this learning experience? How will this experience change how you approach similar experiences in the future (during school life, work life, etc ...)? How might you extend your knowledge related to this topic area?

\section{Data analysis}

This study followed a qualitative approach using thematic analysis. According to Braun and Clarke (2006), a thematic analysis is a foundational qualitative method for discovering patterns within the data. It should be conducted using a step by step process. The researchers first became thoroughly familiar with the data to generate initial codes using NVivo12 qualitative analysis software. Upon the completion of coding, themes were generated. As a final step, the researchers revised the themes and wrote the report. The researchers debated the strengths and weaknesses between strictly conceptualizing themes without quotes and heavily using quotes to provide readers with evidence. It was decided to merge the two philosophies and meet in the middle. Quotes were drawn from the data to allow readers to make their own judgements on credibility, accuracy, and fairness (Corden \& Sainsbury, 2006).

\section{Results}

A summary of the results are provided in Table 1 and detailed results are provided in the remainder of this section.

\section{Pre- and post- philosophy of learning statements}

Analysis of the pre- and post-philosophy of learning statements revealed a variety of themes between the pre- and post-statements, in addition to noteworthy differences between the pre- and post-statements.

\section{Learning perspective: weaknesses (pre) vs. strengths (post)}

Before participating in the food science and technology focused educational experience, students generally reported to primarily assess the ability to complete the learning experience from a deficits perspective with a particular focus on identifying challenges and personal weaknesses. However, after completing the food science and technology focused educational experience, students generally reported to primarily assess the ability to complete the learning experience from a strengths perspective with a particular focus on learning from past experiences. Example responses are as follows:

Pre-participation

- I typically first take a look at any obstacles that might stand in my way or prevent me from completing it on time.

- I look at the parts that I don't fully understand and do my best to learn about those different aspects. 
Table 1 Summary of results

4.1 Pre- and Post-Philosophy of Learning Statements

4.1.1 Learning Perspective: Weaknesses (Pre) vs. - Before participating in the learning experience, students Strengths (Post)

generally reported to primarily assess the ability to complete the learning experience from a deficits perspective with a particular focus on identifying challenges and personal weaknesses.

- After completing the learning experience, students generally reported to primarily assess the ability to complete the learning experience from a strengths perspective with a particular focus on learning from past experiences.

4.1.2 Value of Learning: All Learning is Worth It (Pre) vs. Value of Learning Depends (Post)

- Before participating in the learning experience, students generally reported a whimsical, open-minded and optimistic perspective that all learning was "worth it".

- After completing the learning experience, students generally reported a more realistic approach to learning valuation which aligns to practical and future applications.

4.1.3 Approach to Similar Learning Experiences: No Difference (Pre) vs. Alternative Way (Post)

- Before participating in the learning experience, students generally reported a "no" or "maybe" perspective on approaching future learning in an alternative way.

- After completing the learning experience, students generally responded positively to approaching future learning experiences in an alternative way.

4.1.4 Commonalities: Limited Difference Between Pre and Post

- Both before and after, students reported on the need to assess time availability and the benefit of chunking out tasks.

- Both before and after, students reported on a preferred learning style. However, this learning style varied from one student to the next.

4.2 Reflection Prompts

4.2.1 Workplace Connections

- Throughout the essays, students were able to connect the artifact development and reflection assignment to what they perceive employers are looking for in the workplace.

4.2.2 Importance of Communication

- Throughout the essays, students were able to demonstrate a newfound recognition around the importance of oral, written and visual communication.

4.2.3 Communication Technology Skill Development

- Throughout the essays, students were able to explain self-perceived skill development related to written and visual communication technologies.

- I compare what is required within the task to my strengths and weaknesses. Once I see where my reach falls I attack my weaknesses with respect to accomplish the task and while doing so build on my strengths. I hypothesize that this methodology with eventually eliminate my weaknesses.

- While there are usually barriers with any opportunity, I do my best to overcome these.

- I believe things I do now could be beneficial to my future so I will try to get by these barriers to be able to learn.

- Even if there are barriers present, I try to work with them.

\section{Post-participation}

- I tend to look at the learning opportunity and asses what I would be best at first.

That being said, I play to my strengths when I can. 
- I assess by looking firstly at the things that I am capable of which are applicable to the situation at hand.

- [I assess barriers and motivators based on] my experience on prior activities.

- When faced with a learning opportunity, I assess barriers and motivators based on my past knowledge.

Value of learning: all learning is worth it (pre) vs. value of learning depends (post)

Before participating in the food science and technology focused educational experience, students generally reported a whimsical, open-minded and optimistic perspective that all learning was "worth it". However, after completing the food science and technology focused educational experience, students generally reported a more realistic approach to learning valuation which aligns to practical and future applications. Example responses are as follows:

Pre-participation

- Any knowledge gained has the potential to be "worth learning".

- Anything is worth learning.

- It's always worth learning. Always.

- I believe in being well rounded so all new information can be useful.

- Everything is worth learning.

- In my opinion, almost everything is worth learning, for good or bad.

- In my opinion, learning is always worth it.

- Every piece of information is meaningful, especially in a classroom setting.

Post-participation

- This allowed me to look back on what I had learned and relate it to my current life and future.

- All knowledge is important except for the knowledge you will never use again.

- If it's something I can do again, and will do again.

- I also tend to evaluate whether something was worth learning based on the amount of time and effort I put into it compared to the learning or experience I gained from it.

- This allowed me to look back on what I had learned and relate it to my current life and future.

- At the end of a project, I think about what information I now know vs what I knew in the beginning of the project. If there isn't too much new or revealing information at the end of the project that would have drastically influenced it in the beginning, then I would probably refer to it as a job instead of a learning experience.

Approach to similar learning experiences: no difference (pre) vs. alternative way (post)

Between pre- and post-responses, students had varied perspectives on how they might approach similar learning experiences differently. Prior to participating in the food science and technology focused educational experience, students generally reported a "no" or "maybe" perspective on approaching future learning in an alternative way. After completing the food science and technology focused educational experience, students generally responded positively to approaching future learning experiences in an alternative way. Example responses are as follows: 
Pre-participation

- Alot of times if it bores me or I pawn [learning] off as not useful, I don't put in a lot of effort, but could find out later it's more important than I might have first imagined.

- I would not overload myself. I try to do too many things at once and sleep is often what suffers. I will focus on learning but can only do so much at once.

- If I was to participate in a learning experience again I would approach it the same way.

- Maybe, I'm pretty confident in my learning style.

- I don't really know. I might try to look for improvements.

- No I wouldn't. I went it with an open mind and learned as much as I could and believe I benefited greatly from it. I believe going into it with an open mind helped increased how much I learned.

- I think I would try to approach everything the same way. I think being consistent is very important, especially when it comes to learning. Whether it is consistent practice or consistent review.

Post-participation

- I would improve this learning experience by trying to outright incorporate some of my other experiences. I have done many projects and assignments and can apply them to a broad base of topics and competencies. I would also have completed the reflections closer to the time of their assignment.

- I would approach the learning experience in a similar matter, but not the exact way.

- Obviously, I think any human would do it in a different way. You can't even call it a learning experience if you do the same learning again, then it would just be called an experience. You have to do approach another way or whats the point of the experience in general.

- My approach would be relative per the assignment, however I would have communicated with the instructors much earlier regarding my preferences and needs on certain things.

- I would approach the experience in a more hands on light.

\section{Commonalities: limited difference between pre and post}

It is important to note the commonality between the pre- and post-responses related to the ability to self-assess. Both before and after, students reported an assessment of time availability and the benefit of chunking out tasks. Examples are as follows:

- I use motivation to understand and complete these tasks, and attempt to do this "within a timely manner" by creating a schedule that works through any necessities that come with the assignment or the completion process.

- This in turn, will allow you to learn the most in the shortest amount of time.

- When faced with a learning opportunity being able to not procrastinate helps a lot. 
- I would break down the tasks into smaller chunks and do it step by step and set an overall timeline with all the deadlines so that I can have a better idea of what I'm dealing with and have an upper hand in facing potential road blocks.

An analysis of comparing and contrasting the pre- to post-responses related to one's overall approach to learning resulted in limited differences. There were some noteworthy similarities between the pre- and post-responses related to a general variety towards a preferred learning style. Examples are as follows:

- When presented with a new topic I take notes on the most important things said that day. I then go home and read it over a couple of times.

- I learn best by watching as well as doing so if there is a way to learn by either of those methods that is how I will approach the less understood topic.

- I really try to learn the curve of something before I go into it. To me, it's a lot of talking with others who already went through it.

- I learn through hands on experience and projects to have a better understanding of the subject matter.

- I am a very interactive learner. I like to experience what I learn. To assist in understanding, [I like] explaining and eventually share/teach the content.

- I like to learn through hands-on experience, discussion, and with a focus on interesting topics.

- Also the reflections after each skill helped me go back and reevaluate what I had learned.

- I know my approach to learning is and has always been visual related. I learn quickly and best with colors and designs incorporated in the technical information.

\section{Reflection prompts}

Throughout the semester, students were required to submit four essays responding to reflection prompts linked to learning activities related to the innovation and technology frameworks. Analysis of the essays produced in response to the reflection prompts revealed three key themes: (1) workplace connections, (2) importance of communication, and (3) communication technology skill development.

\section{Workplace connections}

Throughout the essays, students were able to connect the artifact development and reflection assignment to what they perceive employers are looking for in the workplace. Example responses are as follows:

- The ability to comprehensively problem-solve and ask inquisitive and properly-pointed questions is instrumental in every field one can work. Ideally, I will one day wind up working in the field of conflict, so both of these skills will be needed an incredible amount. In such a high-stress environment as conflict (specifically disaster situations), it would be foolish to send someone not a master in both skills. 
- If I found a career in animation, I may need to use systems thinking to decide the best way to develop a new movie or television show that would appeal to viewers of the targeted archetype.

- If I make myself a highly proficient systems thinking designer, I could find opportunities in a process, schedule, or hierarchy to save my employer time, money, and/or make it all safer. Those three improvements are achievable without any modifications to an existing product, which compounds the added value.

- If I were to find my future in marketing, I would most likely have to use systems thinking to develop a convincing advertising campaign by presenting why people need things, and how these things would help.

\section{Importance of communication}

Throughout the essays, students were able to demonstrate a newfound recognition around the importance of oral, written and visual communication. Example responses are as follows:

- [This canvas] allows us to plan ahead and make sure our needs are met before we spend money, time, and other valuable resources. It is a lot simpler to ask your archetype, partners, or boss what they suggest before building a prototype.

- If a relationship system has all the resources and support in the world, but no communication, it will smother and die. As if humans, engineers for that matter, didn't have enough problems communicating, try to contemplate the ideation of a new technology, that only you have seen or in your mind, and it must be conveyed.

- Even though I have conducted interviews before, I still did have anxiety about the process. It was a little intimidating to me. I think I will always have some anxiety talking to people about my ideas, but I am better-versed in the process, which I thought would make this assignment slightly easier.

- While the information is what's important, it is also important to have an attractive canvas that is clean and easy to look at.

- One of the most important things I took from this was the discomfort I had to present my ideas. I understand this is a real world skill and that it is very necessary to use in the work world, but I struggled with it. I did not want to present myself that way with false flattery or the promise of something, like money or food, in return for feedback. I learned I would much rather slip my idea into conversation and ask for an honest opinion on it with nothing in return. I will have to develop this skill in the future; it is something I will have to work on.

- Filling out my Business Model Canvas after the interviews, I regained my appreciation for why we do user interviews. I immediately saw where my classmates, teachers and neighbors and I agreed and where our opinions strayed.

- Within this assignment, I do not believe I mastered inquiry, but I do believe it opened my eyes in that asking surface-area questions are not the only action that can be taken when it comes to interviewing a subject. There are always deeper questions to ask. 
- Whenever I see a problem with multiple different directions I will layout the details in a input, processing, and output with feedback tree. This will help me scope the problem and make my most informed decision.

- The next time that I need to design something for class I will make sure to include as much user interaction as possible.

- While doing the project, I regretted not asking more through and expansive questions. I should have asked for more elaboration on answers so I had more data and knowledge to work with. Next time I have to talk with someone for a project of assignment, I will be sure to use my time wisely and discuss as much as possible.

- Working in a team allows many different perspectives and viewpoints to come together to solve one complex problem, but in order to be successful you need to be able to listen to feedback and implement the feedback into your solution.

- I learned that I struggled with asking the right questions as I felt my partner did this better than I did. I also observed how they were asking the questions and used that to ask them questions later in the process. That was more productive. In this way, I believe I did improve my ability to be a better design thinker and ask better questions allowing me to get closer to the solution.

- I also learned that the variation in visual interpretation is similar to the multiple variants of quantitative data and, similarly, professional preference and variation have a huge influence in the industry standard.

\section{Communication technology skill development}

Throughout the essays, students were able to explain self-perceived skill development related to written and visual communication technologies. Example responses are as follows:

- After this assignment, I think I did learn how to step up graphics in an assignment and learned how to add just a few small touches that take the assignment up a level.

- While completing the assignment I struggled a bit with the way Powerpoint layouts are used. However, I saw that when I tried to center objects, Powerpoint has the snap in to place vertical and horizontal rulers which was much appreciated.

- I learned a lot of new keyboard shortcuts when making my layouts which was very fun.

- I know that I am not the best person for visual design, at least not with an online platform. I feel as though this assignment helped to increase my level of design in things such as this presentation, and my ability to summarize info to the bare minimum.

- Pdfs are a good way of saving visual representations because formatting stays consistent across viewing platforms.

- If I really wanted to prove value of myself, I would step out of the comfort zone. I would attempt to utilize a different software that I am not as comfortable with to improve my level of proficiencies when it comes to creating a simple chart.

- I felt that I built my graphics and design skills through some trial and error. 


\section{Discussion}

Analysis of the pre- and post- philosophy of learning statements and reflection prompts indicate that the food science and technology focused educational experiences had the potential of transforming their self-reported perspectives related to self-regulated learning, connecting the topics to the real-world and communicating. Through this two-course learning experiences, students recognized new weaknesses and strengths, understood the values of learning and reflected on themselves for future improvements. In general, students shifted their perspective from the focus on weaknesses to the focus on strengths, acknowledged the values of more practical and applicable learning experiences, and became positive about approaching future learning experiences in an alternative way.

How can innovative teaching methodologies be applied to food science and technology focused learning experiences to improve student learning outcomes?

In summary, prior to learning the students believed that all learning was worth it, displayed a greater focus on their weaknesses when developing a plan of attack for assignments, and suggested and overall confidence in their current approach to learning. However, after the learning experience, students portrayed a more realistic notion of the value related to learning, communicated an increased awareness of focusing on strengths when developing a plan of attack for assignments, and indicated a greater openness to trying things differently with respect to their approach to learning. In general, these findings are not particularly surprising and are consistent with the literature related to the benefits of integrating self-regulated learning into the classroom (Ambrose, Bridges, Lovett, DiPietro, \& Norman, 2010).

How can food science and technology focused learning experiences encourage students to connect and extend innovation and design frameworks to real-world settings?

The overall theme of workplace connections attributed to the students' ability to translate how the assignments might assist them in the real-world. In general, the students were very specific about identifying their future career path (e.g., marketing, animation, systems design engineer) and implications for applying lessons learned in the specific career path. Thinking about one's self as a future marketing professional, for example, is similar to the research around visualization which has been significantly studied in sports. In training for and completing a marathon, visualization and mental preparation is critical and increases the likelihood of success. Similarly, when a student can visualize him or herself in an actual job and mentally integrate classroom topics into that particular job, it has the potential to increase persistence and completion of the degree. The notion of visualization has been studied within the career counseling field (Hansen, 2003), however, the literature is limited to higher education.

How can the integration of a communication requirement into food science and focused learning experiences develop skills related to oral, written and visual communication? In general, students acknowledged the importance and benefits of communication; in addition, students reported skill development gains with communication-related 
software technology. Students described the advantages of effectively communicating from both an oral (e.g., interviews), written and visual (e.g., canvases) perspective. Although this finding is not particularly surprising, it was a positive takeaway to see how the students' abilities to communicate changed throughout the semester. Furthermore, it was encouraging to see how the students engaged with and reported skill development with the communication-related software technologies throughout the semester.

\section{Conclusions}

\section{Summary and contributions}

The purpose of this study is to respond to the following research questions:

- How can innovative teaching methodologies be applied to food science and technology focused learning experiences to improve student learning outcomes?

- How can food science and technology focused learning experiences encourage students to connect and extend innovation and design frameworks to real-world settings?

- How can the integration of a communication requirement into food science and focused learning experiences develop skills related to oral, written and visual communication?

Innovation-thinking plays a vital role for students to not only learn and understand the technical skills, but also identify a problem, discover a solution, and communicate the value proposition. In this study, innovation-thinking frameworks were integrated into transdisciplinary engineering and technology classrooms with a topic of food science and technology, exploring design within the context of food science and technology. In summary, the pre- and post- philosophy of learning statements and reflection prompts, offer interesting insights into the benefit of integrating self-regulated learning, visualization, and communication technology into future food-related education programs.

This paper makes several contributions. First, it provides an example of how the topic of food science and technology can be integrated into a non-food focused design course. Furthermore, as summarized in Table 1, this approach results in positive outcomes demonstrating the potential of transforming student self-reported perspectives related to self-regulated learning, connecting the topics to the real-world and communicating. Second, it provides an example of how instructors can work together towards a complimentary two-course learning experience in food science and technology. Given the holistic and transdisciplinary nature of food science and technology, this topic lends itself to collaborative works across many different types of courses. Third, the scaffold approach to innovation and new product development was intentionally applied to guide students from (a) System's Thinking - big picture, holistic perspective to (b) Design Thinking - human-centered approach to problem solving to (c) Problem-Market Fit Analysis - value proposition identification, connecting customer needs to features of the product bundle to (d) Business Model Development - identifying and evaluating key abilities required to support bringing a new product to market. This approach allowed students to recognize why the learning activity was important outside of the 
classroom particularly in relation to workforce preparation and securing future employment.

\section{Lessons learned and recommendations for other educators}

It is important to note a few challenges faced throughout the semester. Due to the transdisciplinary nature of the students, it was difficult to align course learning outcomes with the particular interests related to all student backgrounds. In the end, it was decided to offer the courses with a variety of topics from basic food science and evolution of food crossing the gamut from humanities to technologies. It was evident that some students were more interested in technology-focused topics and others were more interested in humanities-focused topics. For example, some students had a greater appreciation for the humanities portion of the class which focused on identifying and discussing examples of cultural and regional-focused cooking equipment. However, these same students appeared to be overwhelmed during the technology portion of the class which introduced new techniques of molding and milling to showcase the process of manufacturing cooking equipment. In the future, we recommend offering options and student choice concerning topics and projects covered in the course. Allowing student choice would likely promote increased engagement and motivation to learn throughout the semester.

Another challenge experienced by the instructors was related to group work. For example, students were divided into two groups of five for the last project which including both a humanities and technology-focused component. It was the intention of the project that all students would work together towards the completion of the required project learning outcomes. Students were supposed to read an entire textbook chosen by the group and identify a problem related to food insecurity, and finally, explore a design of small-scale automated plant growing system to tackle the identified problem. However, instead of completing the project as a group, students with a stronger humanities background read the textbook and identified the problem, and students with a stronger technology background designed and programmed the electromechanical system. In the future, we recommend offering more tutoring and instructor availability to provide one-on-one support to students who may have limited skills within a specific area.

\section{Recommendations for future research}

It is important to note potential limitations of the study. First, the small class sizes, although typical of this program, may limit the generalizability of the results. Additionally, the study was deployed at a single university with a unique bachelor's degree program in transdisciplinary studies. Although many multi-, inter-, and transdisciplinary programs often have similar characteristics, investigating food-related education within the context of a non-standard academic program may limit the generalizability of the results. Thus, future research should be conducted to further validate the study for reliability and repeatability; this could be done by implementing a similar intervention with more students and classes (e.g., increase the sample size), across various engineering and technology programs and courses, and implemented at different universities. Furthermore, future work should continue to investigate how food-related 
education can be used within multi-, inter-, and transdisciplinary programs to improve self-regulated learning, visualization, and exposure and skill development with information and communication technologies. Finally, future research should explore a variety of assessment and evaluation approaches including a student satisfaction survey and different reflection prompts, to name a few; and future research should explore different course designs and food topic areas.

\section{Implications}

Although our focus was on increasing student awareness and application of innovation-thinking frameworks within the context of food science and technology, we are confident that the topic of food would likely be successful outside of the technology and design-focused classroom. Thus, at other institutions, we recommend that faculty consider the use of food as a context which can be easily incorporated into other disciplines and topic areas, such as natural sciences, social sciences, and humanities faculty, to name a few other disciplines. Furthermore, we are optimistic that the findings provide relevance for integrating information and communications technologies into the student higher education experience, and extending practicality beyond the curricular classroom to other extracurricular experiences including seminars, workshops, and student research experiences.

Acknowledgements

Not applicable

Authors' contributions

LB conceptualized the study and was a major contributor in writing the manuscript. SE performed the initial data analysis and literature review. All authors read and approved the final manuscript.

\section{Funding}

The authors declare that they have no funding to report.

\section{Availability of data and materials}

The data that support the findings of this study are available on request from the corresponding author [LB]. The data are not publicly available due to them containing information that could compromise research participant privacy/ consent.

\section{Competing interests}

The authors declare that they have no competing interests.

Received: 8 April 2019 Accepted: 18 July 2019

Published online: 18 September 2019

\section{References}

Ambrose, S., Bridges, M., Lovett, M., DiPietro, M., \& Norman, M. (2010). How learning works. Hoboken: Jossey-Bass.

Barlett, P. F. (2011). Campus sustainable food projects: Critique and engagement. American Anthropologist, 113(1), $101-115$.

Barlett, P. F., Anderson, E., Boyer, J. C., Brunckhorst, D., Princen, T., \& Barlett, P. B. (2008). Reason and reenchantment in cultural change: Sustainability in higher education. Current Anthropology, 49(6), 1077-1098.

Beiler, M. R. O. (2015). Integrating innovation and entrepreneurship principles into the civil engineering curriculum. Journal of Professional Issues in Engineering Education and Practice, 141(3):04014014.

Berger, M., Scott, E., Axe, J., \& Hawkins, I. (2013). World challenge: Engaging sophomores in an intensive, interdisciplinary course. International Journal of Teaching and Learning in Higher Education, 25(3), 333-345.

Bosman, L., \& Fernhaber, S. (2018). Teaching the entrepreneurial mindset to engineers. Switzerland: Springer International Publishing

Braun, V., \& Clarke, V. (2006). Using thematic analysis in psychology. Qualitative Research in Psychology, 3(2), 77-101.

Brekken, C. A., Peterson, H. H., King, R. P., \& Conner, D. (2018). Writing a recipe for teaching sustainable food systems: Lessons from Three University courses. Sustainability, 10(6), 1-19.

Brown, T. (2009). Change by design: how design thinking transforms organizations and inspires innovation. New York: Harper Collins.

Brundiers, K., Wiek, A., \& Redman, C. L. (2010). Real-world learning opportunities in sustainability: From classroom into the real world. International Journal of Sustainability in Higher Education, 11(4), 308-324. 
Burley, D., Coker, E., May, B., McCarty, T., Dickerson, E., Milligan, B., ... Hortman, R. (2016). Taking the challenge for real food: Student engagement in procuring sustainably produced food on campus. Journal of Agriculture, Food Systems, and Community Development, 7(1), 71-87.

Burns, H. (2011). Teaching for transformation: (Re) designing sustainability courses based on ecological principles. Journal of Sustainability Education, 2, 1-15.

Campbell-Platt, G. (2017). Food science and technology. Chichester: University of Reading, UK; Wiley-Blackwell.

Clark, B., \& Button, C. (2011). Sustainability transdisciplinary education model: Interface of arts, science, and community (STEM). International Journal of Sustainability in Higher Education, 12(1), 41-54.

Clark, S., Byker, C., Niewolny, K., \& Helms, J. (2013). Framing an undergraduate minor through the civic agriculture and food systems curriculum. NACTA Journal, 57(2), 56.

Cohen, N. (2010). Designing the sustainable foodshed: A cross-disciplinary undergraduate environmental studies course. Innovative Higher Education, 35(1), 51-60. https://doi.org/10.1007/s10755-009-9126-z.

Corden, A., \& Sainsbury, R. (2006). Using verbatim quotations in reporting qualitative social research: researchers' views. York: University of York.

Galt, R. E., Clark, S. F., \& Parr, D. (2016). Engaging values in sustainable agriculture and food systems education: Toward an explicitly values-based pedagogical approach. Journal of Agriculture, Food Systems, and Community Development, 2(3), 43-54.

Galt, R. E., Parr, D., Kim, J. V. S., Beckett, J., Lickter, M., \& Ballard, H. (2013). Transformative food systems education in a land-grant college of agriculture: The importance of learner-centered inquiries. Agriculture and Human Values, 30(1), 129-142.

Grossman, J., Sherard, M., Prohn, S. M., Bradley, L., Goodell, L. S., \& Andrew, K. (2012). An exploratory analysis of studentcommunity interactions in urban agriculture. Journal of Higher Education Outreach and Engagement, 16(2), 179-196.

Hansen, S. S. (2003). Career counselors as advocates and change agents for equality. The Career Development Quarterly, 52(1), 43-53.

Jacobsen, K., Niewolny, K., Schroeder-Moreno, M., Van Horn, M., Harmon, A. H., Chen Fanslow, Y., ... Parr, D. (2012). Sustainable agriculture undergraduate degree programs: A land-grant university mission. Journal of Agriculture, Food Stuffs, and Community Development, 2(3), 13-26.

Kolodinsky, J., Fukagawa, N. K., Roche, E., Belliveau, C., \& Johnson, H. (2016). Walking the talk of food systems at a small landgrant university: Overcoming process barriers to a transdisciplinary approach. Journal of Agriculture, Food Systems, and Community Development, 2(3), 149-159.

LaCharite, K. (2016). Re-visioning agriculture in higher education: The role of campus agriculture initiatives in sustainability education. Agriculture and Human Values, 33(3), 521-535.

Osterwalder, A., \& Pigneur, Y. (2010). Business model generation: a handbook for visionaries, game changers, and challengers. Hoboken: Wiley.

Osterwalder, A., Pigneur, Y., Bernarda, G., \& Smith, A. (2014). Value proposition design: How to create products and services customers want. Hoboken: Wiley.

Parr, D. M., \& Trexler, C. J. (2011). Students' experiential learning and use of student farms in sustainable agriculture education. Journal of Natural Resources \& Life Sciences Education, 40(1), 172-180.

Seddon, J., \& Caulkin, S. (2007). Systems thinking, lean production and action learning. Action Learning: Research and Practice, $4(1), 9-24$.

Sibbel, A. (2009). Pathways towards sustainability through higher education. International Journal of Sustainability in Higher Education, 10(1), 68-82. https://doi.org/10.1108/14676370910925262.

Valley, W., Wittman, H., Jordan, N., Ahmed, S., \& Galt, R. (2018). An emerging signature pedagogy for sustainable food systems education. Renewable Agriculture and Food Systems, 33(5), 467-480. https://doi.org/10.1017/S1742170517000199.

Wheadon, J., \& Duval-Couetil, N. (2016). Elements of entrepreneurially minded learning: KEEN white paper. The Journal of Engineering Entrepreneurship, 7(3), 17-25.

\section{Publisher's Note}

Springer Nature remains neutral with regard to jurisdictional claims in published maps and institutional affiliations.

\section{Submit your manuscript to a SpringerOpen ${ }^{\circ}$ journal and benefit from:}

- Convenient online submission

- Rigorous peer review

- Open access: articles freely available online

High visibility within the field

- Retaining the copyright to your article

Submit your next manuscript at $\boldsymbol{s p r i n g e r o p e n . c o m ~}$ 